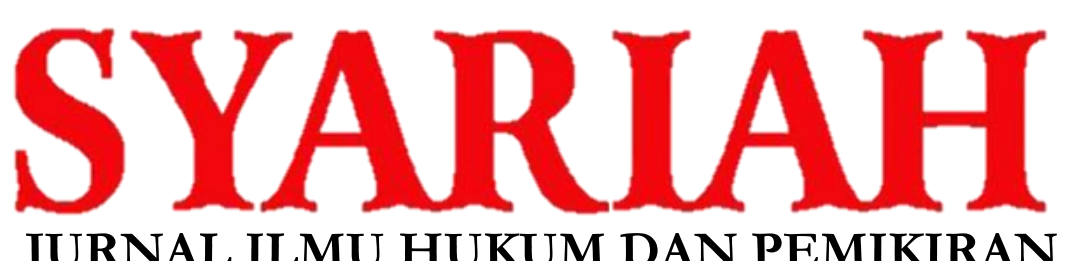

Volome 17, Nomor 1, Januari - Juni 2017

Table of Contents Articles

HAK DAN STATUS ANAK SYUBHAT DALAM PENIKAHAN

Fahmi Al Amruzi

TINDAK PIDANA PENISTAAN AGAMA PERSPEKTIF HUKUM ISLAM DAN HUKUM POSITIF INDONESIA Rina Septiani

RELASI SETARA ANTARA LAKI-LAKI DAN PEREMPUAN

DALAM KASUS KEWARISAN ISLAM (FARAIDH)

Wahidah 


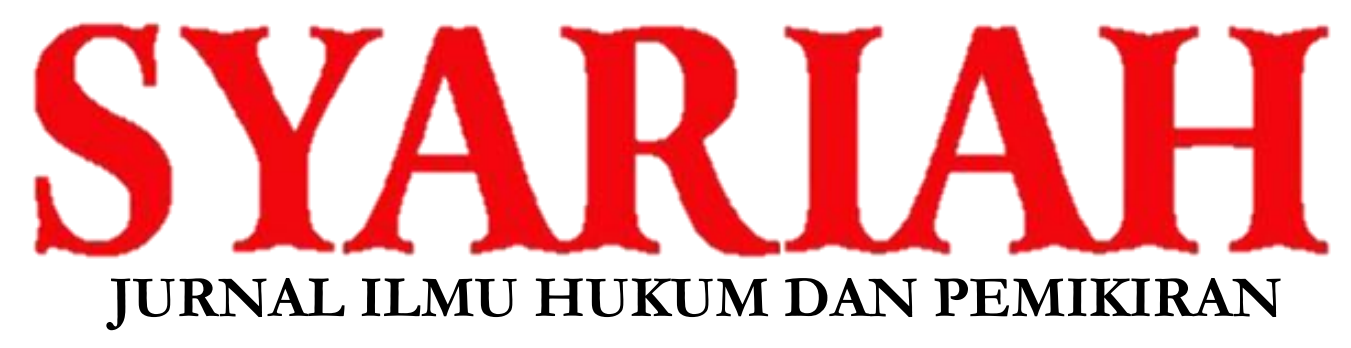




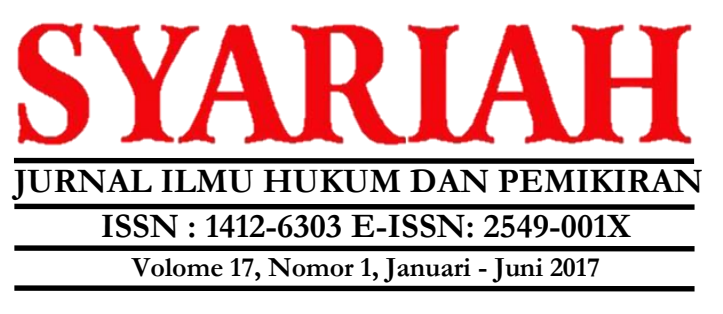

\section{Editor-In-Chief}

Anwar Hafidzi, (orcid/0000-0002-8259-0512) Antasari State Islamic University of Banjarmasin, Indonesia

\section{Managing Editor}

Fajrul IImi, Antasari State Islamic University of Banjarmasin, Indonesia

\section{Editorial Board}

Euis Nurlaelawati, (SCOPUS ID: 56247081700; h-index: 1); Sunan Kalijaga State Islamic University (UIN) of Yogyakarta, Indonesia, Indonesia

Mukhammad Zamzami, Fakultas Ushuluddin dan Filsafat Universitas Islam Negeri Sunan Ampel, Indonesia

Muhammad Fahmi Al-Amruzi, Antasari State Islamic University of Banjarmasin, Indonesia

Kasjim Salenda, Universitas Islam Negeri Alauddin, Makassar, Indonesia

Ratno Lukito, (SCOPUS Author ID: 56053499700) State Islamic University Sunan Kalijaga Yogyakarta, Indonesia, Indonesia

Dian Indriyani, Sekolah Tinggi Keguruan dan Ilmu Pendidikan (STKIP) Muhammadiyah, Manokwari, Indonesia

Ridwan Khairandy, Fakultas Hukum Universitas Islam Indonesia, Yogyakarta, Indonesia Mohd Mufid, Sunan Ampel State Islamic University of Surabaya, Jawa Timur, Indonesia Al Makin, Sunan Kalijaga State Islamic University of Yogyakarta, Indonesia

\section{Editors}

Aik Ihsan Anshori, Sekolah Tinggi Islam Nahdhatul Ulama (STISNU) Tangerang, Indonesia, Indonesia

Rina Septiani, Fakultas Hukum Universitas Tama Jagakarsa, Kota Jakarta Selatan, Daerah Khusus Ibukota Jakarta, Indonesia, Indonesia 
Edi Gunawan, Intitut Agama Islam Negeri Manado, Sulawesi Utara, Indonesia Rif'atul Hidayat, Universitas Nahdhatul Ulama, Kabupaten Banjar, Indonesia Miftah Faridh, Antasari State Islamic University of Banjarmasin, Indonesia Nuril Khasyi'in, Antasari State Islamic University of Banjarmasin, Indonesia

\section{Assistant to the Editors}

Tuti Hasanah, Fakultas Syariah, Antasari State Islamic University of Banjarmasin, Indonesia Arabic Language Advisor

Muhammad Hikam, Antasari State Islamic University of Banjarmasin, Indonesia

\section{English Language Advisor}

Martina Purnanisa, Fakultas Syariah dan Ekonomi Islam Antasari State Islamic University of Banjarmasin, Indonesia

Fawait Afnani, Antasari State Islamic University of Banjarmasin, Indonesia 


\title{
TINDAK PIDANA PENISTAAN AGAMA PERSPEKTIF HUKUM ISLAM DAN HUKUM POSITIF INDONESIA
}

\author{
Oleh: \\ Rina Septiani \\ Universitas Tama Jagakarsa \\ Jalan Letjen TB. Simatupang No. 152, Tanjung Barat, Jagakarsa, Jakarta Selatan, 12530 \\ E-mail: septianir35@gmail.com
}

\begin{abstract}
Religion is a belief embraced by everyone who acknowledges the existence of god and every country has people who hold different beliefs every religious person will surely carry out his religious teachings in accordance with the provisions contained in his religion, as well as Islam is a religion that is held by the majority of Indonesian Muslims, has rules to respect the religion of others and has a punishment for people who deliberately declare themselves apostate or out of the Islamic religion biased diqiaskan with desecration of Islam while in positive law Indonesia to tarnish the religion of others also regulated in the Criminal Code
\end{abstract}

Keywords: Apostasy, religion, law, criminal, KUHP

\begin{abstract}
Abstrak: Agama merupakan kepercayaan yang dianut oleh setiap orang yang mengakui adanya tuhan dan setiap negara memiliki warga yang menganut kepercayaan yang berbedabeda setiap orang yang beragama pasti akan menjalankan ajaran agamanya sesuai dengan ketentuan yang terdapat dalam agama yang dianutnya, begitu pun dengan Islam yang merupakan agama yang dianut oleh mayoritas umat muslim Indonesia, memiliki aturan untuk menghormati agama orang lain serta memiliki hukuman bagi umat yang dengan sengaja menyatakan dirinya murtad atau keluar dari agama islam yang bias diqiaskan dengan penodaan terhadap agama Islam sedangkan dalam hukum positif Indonesia menodai agama orang lain juga diatur dalam KUHP
\end{abstract}

Kata kunci: Murtad, agama, hukum, pidana, KUHP

\section{Pendahuluan}

Indonesia merupakan negara yang memiliki lima agama yang diakui dan setiap agama memiliki tuntunan acuan serta aturan yang harus ditaati oleh setiap pemeluk agamanya, di dalam agama Islam terdapat beberapa pedoman yang harus ditaati yaitu Alquran dan Hadits serta ijma ulama.

Islam merupakan agama rahmatan lil alamin yang didalamnya mengatur bukan hanya mengenai ibadah dengan sang khalik (Hablumminallab) tapi juga diatur mengenai 
hubungan dengan sesama manusia (bablumminannas), hubungan antar sesama pemeluk agama Islam maupun dengan pemeluk agama lain. Apabila seseorang sudah memeluk Agama Islam maka harus mengamalkan ajaran ajaran pokok atau dasar didalamnya.

Ada beberapa kelompok, organisasi atau aliran dalam masyarakat yang menyatakan dirinya bagian dari agama Islam tetapi setelah diteliti lebih jauh aliran tersebut memiliki perbedaan dalam masalah akidah, karena perbedaan tersebut para Ulama di Indonesia menyatakan mereka sebagai aliran sesat dan kaum Muslimin tidak diperbolehkan mengikuti ajarannya. Aliran tersebut diantaranya Ahmadiyah, Salamullah ( Lia Aminuddin AKA Lia Eden ). ${ }^{1}$

Salah satu ciri yang paling fatal dalam aliran al- Qiyadah al- Islamiyah yaitu mereka memiliki syahadat baru. Adapun lafad syahadatnya : Asybadu An Laa Ilaaha Illallaah, Wa Asybadu Anna Al-Masib Al-Mawnd Rasulullah, Tentu sangat bertentangan dengan syahadat Agama Islam yang mengaku Nabi Muhammad SAW sebagai Rasulullah. Sesuai dengan hadits dari Nabi Muhammad SAW :

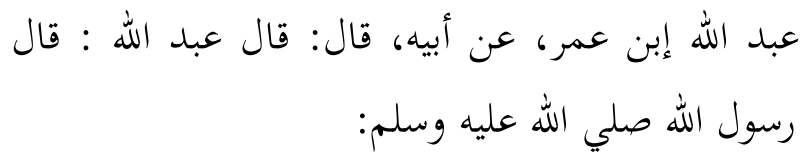

1 Yusuf Ks, “Al-Qiyadah”, artikel ini diakses pada 28 November 2008 dari http://jowo.jw.lt.
بني الإسلام علي خمس . . . شهادة أن لاإله إلا الله وأن محمدا عبده ورسوله (رواه مسلم) 2

Artinya; Diriwayatkan dari Abdullah Bin Umar dari bapaknya, Abdullah berkata bahwa Nabi Muhammad SAW bersabda : Islam ditegakan diatas lima dasar ... bersaksi bahwa tidak ada tuhan yang wajib disembah kecuali Allah dan Nabi Muhammad adalah utusannya ( HR. Muslim )

Sangat bertentangan dengan hadits di atas karena dalam Agama Islam meyakini Nabi Muhammad SAW adalah utusan Allah SWT dan beliau juga sebagai Nabi yang terakhir atau dapat dikatakan sebagai penutup para Nabi . Hal tersebut dijelaskan dalam firman Allah SWT surat Al-Ahzab ayat 40 yang berbunyi :

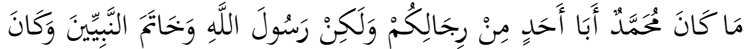

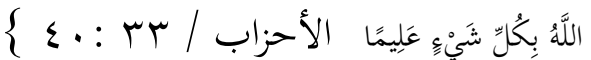

Artinya : "Muhammad itu sekali-kali bukanlah bapak dari seorang laki-laki di antara kamu, tetapi dia adalah Rasulullah dan penutup nabinabi. dan adalah Allah Maha mengetahui segala sesuatu”. ( QS. Al-Ahzab 33 : 40 )

Ayat tersebut menjelaskan bahwa Nabi Muhammad SAW merupakan Nabi dan Rasul yang terakhir dicatat dalam al - Quran dengan ungkapan Khatamaan - Nabiyyin. Apabila seseorang menyatakan dirinya sebagai Nabi setelah beliau, maka dapat dikatakan sebagai

2 Imam Abi al- Husaini Muslim bin al - Hajaj, Shahih Muslim, ( Libanon : Bairut ), 2003, Jus 1, h. 53. 
Nabi palsu. Nabi palsu tidak saja muncul di Negara yang agamis tetapi juga muncul di Negara maju. Hal tersebut menujukkan bahwa banyak orang yang merasa dirinya menjadi pilihan tuhan untuk menjadi pemimpin di dunia. Ajaran - ajaran Nabi palsu banyak menjelma menjadi aliran atau sekte. Ada yang bertahan lama, namun tidak sedikit yang hilang ditelan bumi. Kemunculan Nabi palsu terus hadir dan selalu ada orang - orang yang menjadi pengikutnya, bahkan menjadi angggota militan yang bersedia mengorbankan nyawanya. Nabi palsu tidak saja muncul setelah Rasulullah SAW wafat, bahkan pada saat beliau masih hidup sudah banyak orang yang mengaku dirinya sebagai Nabi, untuk menandingi beliau. Nasib para Nabi palsu bermacam - macam, ada yang digantung mati, dibakar, dirotan, dan ada yang menjadi gila.

Menurut hukum pidana Islam para Nabi palsu dapat diqiyaskan dengan hukuman terhadap orang Murtad. Secara bahasa murtad berarti kembali atau dapat dikatakan orang yang kembali dinamakan murtad. Sesuai dengan firman Allah SWT surat Al - Maidah ayat 21 yang berbunyi :

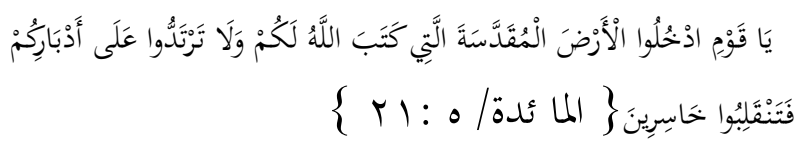

Artinya: "Dan janganlah kamu lari kebelakang (karena takut kepada musuh),
Maka kamu menjadi orang-orang yang merugi”. (QS. Al - Maidah 5: 21 ).

Adapun murtad secara etimologis ialah riddah merupakan isim masdar dari kat( إرتداد ) yang berarti mundur, kembali kebelakang

$$
\text { الردة: الرجوع عن الشيء إلى غيره } 3
$$

Artinya ; riddah ( murtad) adalah kembali dari sesuatu kepada yang lainnya.

Sedangkan menurut Ibrahim Unais dan kawan - kawan dalam kamus al - Munawwir mengemukakan bahwa riddah berasal dari kata : Los, - هsرyang artinya : melempar. ${ }^{4}$

Selanjutnya pengertian riddah oleh Abdul Qadir Audah sebagai berikut :

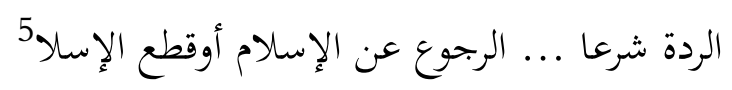

Riddah ialah kembali ( keluar) dari Agama Islam atau memutuskan dari Agama Islam.

Dapat diambil kesimpulan bahwa Riddah adalah suatu perbuatan seseorang muslim yang pada awalnya sudah menyatakan beriman kepada ajaran Allah SWT dan Rasul Nya, serta

3 Muhammad Amin Suma, Pidana Islam di Indonesia Peluang, Prospek, dan Tantangan, (Jakarta: Pustaka Firdaus), 2001, Cet. 1, h. 63.

4 Ahmad Warson Munawwir, al - Munawir Kamus Arab - Indonesia, (Surabaya: Pustaka Progressif, 1997), Cet XIV, h. 489.

5 Abdul Qadir Audah, al - Tasyri al - Jina'i al Islami, (Maktabah: Dar- al - Urbah ), 1963, Jus II, h.706. 
taat kepada perintah dan menjauhkan laranganNya, setelah itu dia keluar dari Agama Islam kepada kekafiran baik dengan niat, perbuatan dan ucapan yang menyebabkan kekafiran.

Dalam KUHP (WVS) sebenarnya tidak ada bab khusus mengenai delik agama meski ada beberapa delik yang sebenarnya dapat dikategorikan sebagai delik agama. Istilah delik agama itu sendiri sebenarnya mengandung beberapa pengertian sebagai delik menurut agama, delik terhadap agama, delik yang berhubungan dengan agama. Oemar Seno Adji yang dikutip Barda Nawawi Arief menyebutkan bahwa delik agama hanya mencakup delik terhadap agama dan delik yang berhubungan dengan agama. Apabila diperhatikan sebenarnya delik menurut agama bukan tidak ada dalam KUHP meski hal itu tidak secara penuh dalam KUHP seperti delik pembunuhan, pencurian, penghinaan dan yang lainnya.

Pasal 156 a sering dijadikan rujukan hakim untuk memutuskan kasus penodaan agama, bunyi selengkapanya adalah Dipidana dengan pidana penjara selama-lamanya 5 tahun, barang siapa dengan sengaja dimuka umum mengeluarkan perasaan atau melakukan perbuatan, yang pada pokoknya bersifat permusuhan, penyalahgunaan atau penodaan terhadap suatu agama yang dianut di Indonesia, dengan maksud agar orang tidak menganut agama apapun juga yang bersendikan ketuhanan yang maha esa.

Pasal tersebut dapat dikategorikan sebagai delik terhadap agama. Asumsinya, yang ingin dilindungi pasal ini, perlu dilindungi dari kemungkinan-kemungkinan perbuatan orang yang bisa merendahkan dan menistakan simbolsimbol agama seperti Tuhan, Nabi, Kitab suci dan sebagainya. Perlu difahami bahwa pasal 156 a tidak berasal dari wetbook van strafrecht (WVS) Belanda, melainkan dari UU No. I / PNPS / 1965 tentang pencegahan dan atau penodaan agama. Pasal 4 Undang-undang tersebut langsung memerintahkan agar ketentuan diatas dimasukkan kedalam KUHP. ${ }^{6}$

Adapun unsur yuridis yang menjadi pertimbangan Hakim Pengadilan Negeri Jakarta Selatan pada kasus tindak pidana penodaan Agama yaitu Kitab Undang - Undang Hukum Pidana ( KUHP ) pada pasal $156 \mathrm{a}^{7}$ sebab menurutnya terdakwa sudah memenuhi unsur unsur didalamnya. Maka Majlis Hakim memberikan putusan No.227/ Pid.B/ 2008/ PN.Jkt.Sel, pada tingkat pertama yang dijatuhkan kepada terdakwa yang bernama AS alias AM alias AA pidana penjara selama 4 ( empat ) tahun, karena dia telah terbukti secara

6 Rumadi, Delik Penodaan Agama dan Kehidupan Beragama Dalam RUU KUHP, (Jakarta : Yayasan Tifa ), 2007, h. 10-12.

7 Moeljatno, Kitab Undang-undang Hukum Pidana, (Jakarta: PT. Bumi Aksara ), 2001, Cet.21, h.61. 
sah dan meyakinkan bersalah melakukakan tindak pidana "Dengan Sengaja Dimuka Umum Melakukan Perbuatan Yang Pada Pokoknya Bersifat Penodaan Terhadap Suatu Agama Yang Dianut Di Indonesia". ${ }^{8}$ Oleh karena itu didalam artikel ini akan dibahas mengenai tindak pidana penodaan agama menurut hukum islam dan hukum positif di Indonesia

\section{Riddah}

Islam memiliki aturan tertentu di dalam Al-quran yaitu lakum dinukum waliadin (untukmu agamamu dan untukku agamaku), berdasarkan hal tersebut maka terdapat aturan mengenai suatu perbuatan seseorang muslim yang pada awalnya sudah menyatakan beriman kepada ajaran Allah SWT dan Rasul Nya, serta taat kepada perintah dan menjauhkan laranganNya, setelah itu dia keluar dari Agama Islam kepada kekafiran baik dengan niat, perbuatan dan ucapan yang menyebabkan kekafiran maka hal tersebut didalam islam dinamakan dengan riddah.

Riddah merupakan isim masdar dari kata (إرتداد) yang berarti mundur, kembali kebelakang.

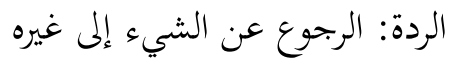

8 Putusan Pengadilan Negeri Jakarta Selatan No.227/Pid.B/2008/PN.Jkt.Sel
Artinya :

Riddah (murtad) adalah kembali dari sesuatu kepada yang lainnya.'

Sedangkan menurut Ibrahim Unais dan kawan kawan dalam kamus al - Mu'jam al- Wasith jilit I mengemukakan bahwa riddah berasal dari kata: رده - ردا- وردة :منعه وصرفه dan memalingkannya. Kemudian menurut istilah syara, pengertian riddah sebagaimana dikemukakan oleh Wahbah Zuhaili adalah sebagai berikut :

وهي شرعا الرجوع عن دين الإسلام إلى الكفر سواء بالنية أوباالفعل المكفر أو بالقول

Riddah menurut syara' adalah kembali dari Agama Islam kepada kekafiran, baik dengan niat, perbuatan yang menyebabakan kekafiran atau dengan ucapan. ${ }^{10}$

Selanjutnya pengertian riddah oleh Abdul Qadir Audah sebagai berikut :

الردة شرعا ... الرجوع عن الإسلام أوقطع الإسلام

Riddah ialah kembali (keluar) dari Agama Islam atau memutuskan dari Agama Islam. ${ }^{11}$

Riddah adalah kembali dari Agama Islam kepada kekafiran, baik dengan niat, perbuatan yang menyebabkan kekafiran atau

9 Muhammad Amin Suma, Pidana Islam di Indonesia Peluang, Prospek, dan Tantangan, ( Jakarta : Pustaka Firdaus ), 2001, Cet. 1, h. 63.

10 Ahmad Wardi Muslich, Hukum Pidana Islam, ( Jakarta : Sinar Garfika ), 2005

11 Abdul Qadir Audah, al - Tasyri al - Jina'I al Islami, ( Maktabah : Dar- al - Urbah ), 1963, Jus II, h.706. 
dengan ucapan. ${ }^{12}$ Seseorang yang melakukan perbuatan Riddah sudah ditetapkan hukumanya di dalam al - Qur' an dan al - Hadist. Mereka dimasukan keneraka untuk selama - lamanya serta mendapatkan azab yang pedih dan hukuman di dunia darahnya halal untuk di tumpahkan. Hal tersebut dijelaskan oleh Allah SWT dalam Surat Al - Baqarah ayat 217 yang berbunyi:

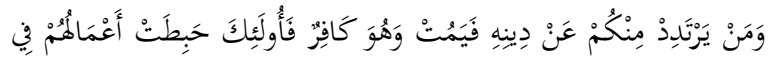

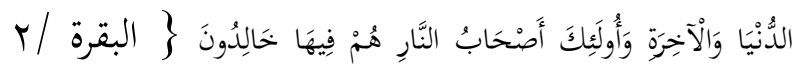

$\{r \mid V:$

Artinya : " barangsiapa yang murtad di antara kamu dari agamanya, lalu dia mati dalam kekafiran, Maka mereka Itulah yang sia-sia amalannya di dunia dan di akhirat, dan mereka Itulah penghuni neraka, mereka kekal di dalamnya". ( QS. Al- Baqarah 2 : 217 ).

Hadits dari Rasulullah saw yang menjelaskan hukuman untuk orang Riddah adalah sebagai berikut :

Hadits dari Mua' dz Ibn Jabal :

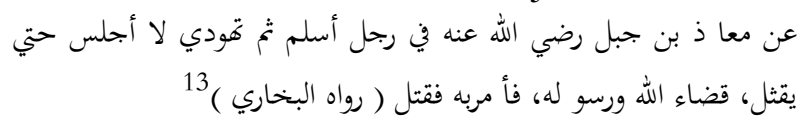

Artinya ; dari Mua' dz Ibn Jabal ra. (ia menceritakan ) tentang adanya seorang laki laki yang telah masuk Islam, kemudian Dia kembali ke Agama Yahudi, Mua' dz Ibn Jabal berkata : aku tidak akan duduk sampai Dia (orang Murtad tersebut) dihukum bunuh, itulah ketetapan Allah dan Rasulnya, lalu orang tersebut diperintahkan untuk dihukum bunuh (HR. Bukhari ).

12 Ahmad Wardi Muslich, Hukum Pidana Islam, h. 119.

13 Abi Hasan Nurudin Muhammad bin Abdul Hadi'i Sannadi'i, Shahih Bukhari, Jus IV, h. 378.
Selanjutnya Hadits dari Ibnu Abbas :

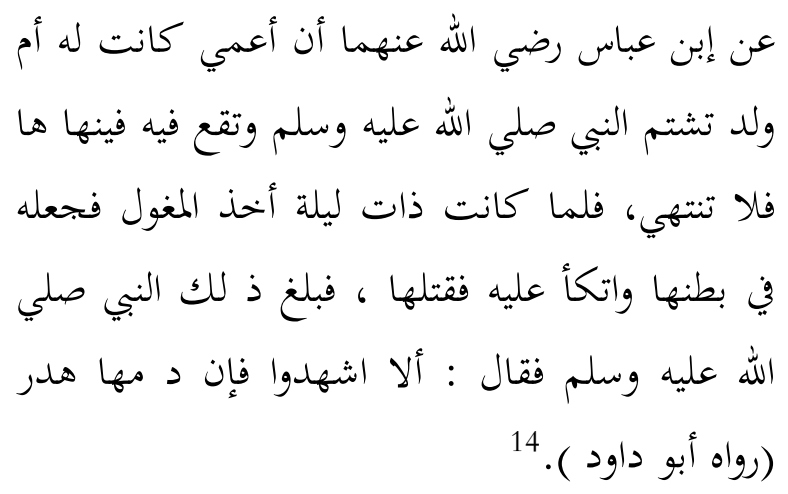

Artinya: dari Ibnu Abbas ra. (ia menceritakan) tentang seseorang buta, Ibu kandungnya adalah wanita hamba sahaya yang melakukan penghinaan terhadap Rasulullah saw. Meskipun telah dilarang, wanita tersebut tidak menghentikan perbuatannya. Dan pada suatu malam, anaknya yang buta itu mengambil semacam benda pegangan lalu diletakannya pada perut wanita itu dan sambil bertelekan pada benda itu dia bunuh wanita tersebut. Sementara Rasulullah datang (menyaksikan) lalu beliau bersabda : lihatlah wanita itu halal darahnya (HR. Abu Dawud).

Dan Hadits dari Ibnu Abbas :

$$
\text { عن إبن عباس رضي الله عنه قال : رسول الله صلي الله عليه وسلم من } 15
$$

Artinya ; dari Ibnu Abbas ra. Ia berkata : bahwa Rasulullah saw bersabda : " barang siapa menukar Agamanya maka bunuhlah Dia”. (HR.Bukhari ).

14 Abi Dawud Sulaiman bin Sajastani, Sunnah Abu Dawud, ( Lebanon : Darul Fiqri, 1994 ), Jus IV, h. 116

15 Abi Hasan Nurudin Muhammad bin Abdul Hadi'i Sannadi'i, Shahih Bukhari, Jus IV, h. 378. 
Syariah: Jurnal Ilmu Hukum dan Pemikiran

Vol. 17. No. 1 Juni 2017

Apabila seseorang melakukan sebuah penghinaan atau penodaan terhadap Nabi Muhammad saw, maka darah orang tersebut halal untuk ditumpahkan. Sesuai dengan riwayat hadits di atas bahwa ada seorang hambasahanya yang melakukan penghinaan terhadap Rasulullah saw, kemudian dia diperintahkan untuk menghentikan perbuatannya akan tetapi dia tidak menjalankan perintahnya. Dan pada suatu malam ada seorang yang buta membawa alat tajam kemudian diletakkan di atas perut wanita tersebut, selanjutnya dia menekannya kemudian wanita itu meninggal sementara Rasulullah saw menyaksiaknnya lalu beliau bersabda: lihatlah wanita itu halal darahnya.

Aturan tersebut tidak boleh dilakukan sebelum pelaku diminta bertobat dari perbuatannya. Menurut pendapat Imam Malik, Mazhab Syafi'I dan Hambali bahwa memintakan orang tersebut untuk bertobat hukumnya adalah wajib. Sedangkan pendapat Mazhab Abu Hanifa hukum memintakan orang Murtad untuk bertobat adalah sunnah.

Meskipun ada sebuah kaidah tentang orang yang murtad untuk bertobat tanpa memandang apakah hal tersebut hukumnya wajib atau sunnah. Imam Malik melarang untuk meminta tobatnya tiga golongan berikut untuk bertobat:

$>$ Orang yang menghina para Nabi dan Rasul atau Malikat, menyindir, mengutuk,
Tindak Pidana Penistaan Agama ...17-31 Rina Septiani

mencacimaki, meremehkan kebenaranya atau hal yang sejenisnya, langsung dihukum mati tanpa diminta tobatnya. Firman Allah SWT surat At - Taubah ayat 65 - 66 yang berbunyi :

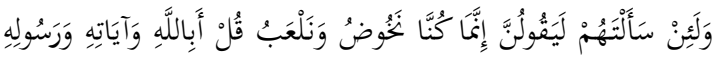

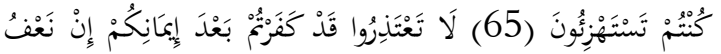

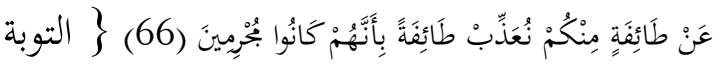
$\{77-09: 7 /$

Artinya : " dan jika kamu tanyakan kepada mereka (tentang apa yang mereka lakukan itu), tentulah mereka akan manjawab, "Sesungguhnya kami hanyalah bersenda gurau dan bermain-main saja." Katakanlah: "Apakah dengan Allah, ayat-ayat-Nya dan rasul-Nya kamu selalu berolok-olok?". Tidak usah kamu minta maaf, Karena kamu kafir sesudah beriman. jika kami memaafkan segolongan kamu (lantaran mereka taubat), niscaya kami akan mengazab golongan (yang lain) disebabkan mereka adalah orang-orang yang selalu berbuat dosa ".( QS. At - Taubah 9 : 65 $66)$.

Tukang sihir yang sihirnya dapat menimbulkan kekufuran tidak diminta bertobat, langsung dihukum mati karena Imam Malik menyamakan hukum tukang sihir yang demikian dengan hukum kafir zindik. Sesuai dengan Hadist dari Rasulullah saw yang bersabda :

$$
\text { عن جند با لسيف ( رواه التر مذل رسول الله صلي الله عليه وسلم حد السا حر ضر }
$$

16 Abi 'Isa Muhammad bin Sûra al - Tirmidzî, Sunnah At-Tirmdzî̀, Jus 6, h. 139. 
Artinya: dari Jandabin, bahwa Rasulullah SAW bersabda: hukuman had bagi Penyihir adalah dipukul dengan pedang atau dihukum bunuh ( HR. at - Tirmidzî ).

Zindik adalah orang yang memperlihatkan keislaman dan menyembunyikan kekufuran. Apabila terbukti kafir dia tidak diminta bertobat dan langsung dihukum mati walaupun dia memperlihatkan tobatnya. ${ }^{17}$ Dalam surat $\mathrm{Al}$ - Baqarah ayat 160 yang berbunyi :

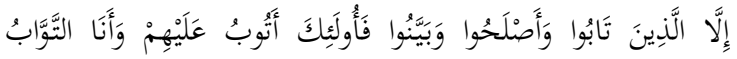
الرَّحيمُ $\}$

Artinya : " kecuali mereka yang Telah Taubat dan mengadakan perbaikan dan menerangkan (kebenaran), Maka terhadap mereka Itulah Aku menerima taubatnya dan Akulah yang Maha menerima Taubat lagi Maha Penyayang ". ( QS. Al - Baqarah 2 : 160 )

\section{Adapun beberapa dampak yang} dilakukan seseorang melakukan riddah adalah yang pertama berdampak kepada hukum pernikahan mereka, apabila suami istri atau salah satu diantaranya Murtad. ${ }^{18}$ Apabila mereka kembali kedalam Islam maka masa iddah pernikahan mereka terus kembali kekal. Adapun

17 Abdul Qadir Audah, Ensiklopedi Hukum Pidana Islam, Judul Asli at - Tasyri al - Jina'I al - Islamiy Muqaranah bil Qanunil Wad' ly, penerjemah, Alie Yafie dkk, ( Jakarta : PT. Karisma Ilmu, 2008 ), Cet I, Jus V, h. 282 -284.

18 Penuh Daly, Hukum Perkawinan Islam, ( Jakarta : PT. Bulan Bintang, 1988 ), Cet I, h. 80. mereka tidak kembali dalam Islam pernikahannya putus terhitung sejak Murtad. Sesuai dengan firman Allah swt dalam surat Al Mumtahanah ayat 10 yang berbunyi :

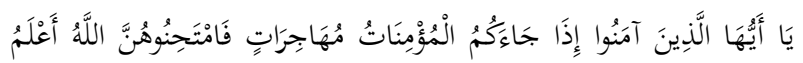

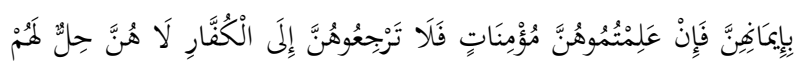

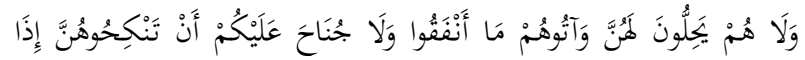

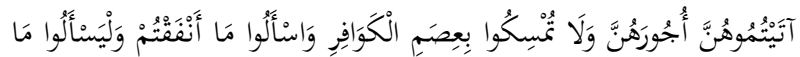

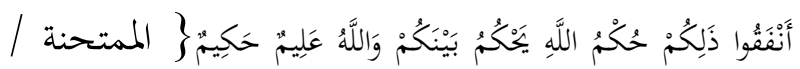
$\{1 \cdot: \cdot 7$

Artinya : "Hai orang-orang yang beriman, apabila datang berhijrah kepadamu perempuanperempuan yang beriman, Maka hendaklah kamu uji (keimanan) mereka. Allah lebih mengetahui tentang keimanan mereka maka jika kamu Telah mengetahui bahwa mereka (benarbenar) beriman Maka janganlah kamu kembalikan mereka kepada (suami-suami mereka) orang-orang kafir. ( QS. Al Mumtahanah $60: 10)$.

\section{Yang kedua penghalang kepada} pewarisan, dalam buku Fiqih Mawaris keadaan seseorang atau suatu pekerjaan yang menyebabkan orang tersebut seharusnya mendapat warisan akan tetapi dia tidak mendapatkannya. Adapun hal - hal yang menggugurkan atau menghilangkan seseorang tersebut antar lain, sebab perbudakan, pembunuhan, berlainan Agama dan berlainan Negara. ${ }^{19}$ Pembahasan dalam penulisan ini

19 Superman Usman, Yusuf Somawinata, Fiqih Mawaris, ( Jakarta : Gaya Media Pratama, 2002 ), Cet II, h. 32 . 
menitik beratkan mengenai perbedaan Agama atau menyamakan dengan orang yang Murtad. Karena kedudukan berlainan Agama sebagai penghalang pewarisan telah menjadi Ijma seluruh Ulama. Hal tersebut karena Hadits Rasulullah saw :

عن أسامة بن زيد قال : قال رسول الله صلي الله عليه وسلم : لا يتوارث

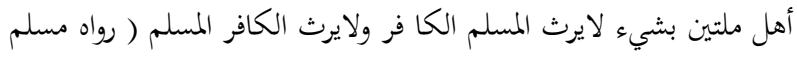
${ }^{20}($

Artinya ; dari Usamata Bin Zaid, bahwa Rasulullah SAW bersabda : tidaklah saling mewarisi sesuatu diantara dua orang yang berlain Agama, orang Islam tidak mewarisi orang dan orang kafir pun tidak mewarisikan orang Islam ( HR. Muslim ).

Berdasarkan pemaparan tersebut riddah dapat diqiaskan dengan Tindak Pidana Penistaan Agama dalam Hukum Pidana Islam. Dalam kamus istilah hukum kata tindak pidana adalah perbuatan yang melanggar Undang - Undang Pidana dan karena bertentangan dengan Undang - Undang yang dilakukan dengan sengaja oleh orang yang dapat dipertanggung jawabkan. Menurut hukum pidana Islam tindak pidana dapat dikatagorikan sebagai Jarimah, yang dimaksud dengan jarimah adalah perbuatan perbuatan yang dilarang oleh syara' yang diancam oleh Allah dengan hukuman had atau ta'zir. ${ }^{21}$

20 Imam Abi Husaini Muslim, Shahih Muslim, Jus III, h. 59.

21 Ahmad Wardi Muslich, Hukum Pidana Islam, (Jakarta : Sinar Grafika, 2005 ), Cet I, h. ix.
Sedangkan sinonim dari kata penistaan/ penodaan yaitu kata penghinaan mengandung pengertian penyerangan dengan sengaja atas kehormatan atau nama baik orang lain baik secara lisan atau tulisan dengan maksud untuk diketahui oleh orang banyak. ${ }^{22}$ Istilah lain dari kata Penodaan ialah menodai dalam Kamus al Munawir kata menodai diambil dari kata ( - قبح - قبح ) yang diartikan keji, memecahkan, menjauhkan, menjadikan buruk, mencela. ${ }^{23}$ Penodaan Agama dalam Islam dimaknai sebagai perbuatan penyimpangan (تحر يف dalam memahami al - Qur' an dan Sunnah. Kata (تحر يف penyimpangan adalah bentuk dari akar kata (حر ف) yang artinya tepi atau sisi. Jadi maksud dari penodaan Agama adalah mengambil dari satu sisi Agama. Dalam terminologis Syari'at kata (تحر يف) berarti mengganti atau merubah makna al - Qur' an dan al - Sunnah dengan makna yang lainnya yang dimaksudkan oleh Nash - nash tersebut. Sedangkan jenis tahrif dibagi menjadi dua segi, yang pertama (تحر يف الفظ) " penyimpangan lafazh " yaitu mengganti lafazh - lafazh nash

22 C. S. T. Kansil, Christine. S. T. Kansil, Kamus Istilah Aneka Hukum, ( Jakarta : PT. Surya Melti Grafika, 2001 ),Cet II, h. 215 - 239.

23 Ahmad Warson Munawwir, al - Munawir Kamus Arab-Indonesia, h. 691. 
dengan lafazh yang lain, yang kedua (تحر يف المعنوي) " penyimpangan makna " ialah mengganti makna nash yang sudah benar dengan makna yang lain. ${ }^{24}$

Dalam buku karya Harun Nasution bahwa Agama berasal dari kata Sanskrit dan menurutnya kata Agama tersusun dari dua kata, $a=$ tidak dan gam $=$ pergi, jadi tidak pergi, tetap di tempat, dan diwarisi turun - temurun. ${ }^{25}$ Selanjutnya kata Agama menurut kamus bahasa Indonesia adalah system yang mengatur tata keimanan ( kepercayaan ) dan kepribadatan kepada Tuhan Yang Maha Kuasa serta tata kaidah yang berhubungan dengan pergaulan manusia serta lingkungannya. ${ }^{26}$

Dan dalam kamus al - Munawir kata

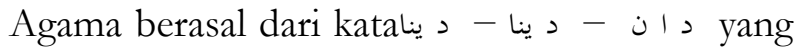
diartikan menghutangi, meminjam dan Agama. ${ }^{27}$ Jadi pengertian tindak pidana penistaan Agama adalah suatu perbuatan yang bertentangan dengan syara' dilakukan dengan sengaja untuk melawan ketentuan hukum

${ }^{24}$ Ibrahim Muhammad bin Abdullah al - Buraikan, Pengantar Studi Aqidah Islam, Penerjemah Anis Matta, (Jakarta : Robbani Perss, 1998 ), h. 106.

25 Harun Nasution, Islam Ditinjau Dari Berbagai Aspek, (Jakarta : Penerbit Universitas Indonesia, 2001 ), Cet I, h.1.

26 Hasan Alwi dkk, Kamus Besar Bahasa Indonesia Edisi Ketiga, (Jakarta : Balai Pustaka, 2005 ), Cet III, h. 12.

27 Ahmad Warson Munawwir, al - Munawir Kamus Arab-Indonesia, h. 437. melalui penyimpangan atau penodaan terhadap Agama baik terhadap lafad atau makna yang terkandung dalam lafad Nashnya.

Agar mengetahui lebih dalam mengenai Tindak Pidana Penistaan Agama dalam Hukum Pidana Islam kami menggunakan metode Qiyas. Qiyas menurut bahasa ukuran, membandingkan, atau menyamakan sesuatau dengan yang lainnya. Menurut istilah membawa hukum yang belum diketahui kepada hukum yang diketahui dalam rangka menetapkan hukum bagi keduanya, atau meniadakan hukum bagi keduanya, disebabkan sesuatu yang menyatukan kaduanya, baik hukum maupun sifat. ${ }^{28}$ Apabila seseorang menggunakan metode qiyas terlebih dulu menerapkan rukun rukun qiyas. Adapun rukun qiyas ada empat antar lain, yang pertama Ashl, kedua Far' $u$, ketiga Hukum Ashl, dan keempat Tllat $^{29}$ Di bawah ini kami akan mencoba untuk menjelaskan dan menerapkan rukun qiyas tersebut.

- Yang pertama Ashl (pokok) adalah suatu peristiwa yang terdapat di dalam Nash al Qur' an dan al - Hadist yang dijadikan tempat mengqiyaskan. Tentang jarimah Riddah yang terdapat dalam Hukum Pidana Islam.

28 Nasrun Haroen, Ushul Fiqih I, (Jakarta : PT. Logos Wacana Ilmu, 1997 ), Cet II, h. 62.

29 Rachmat Syafe'I, Ilmu Ushul Fiqih Untuk UIN, STAIN, PTAIS, (Bandung : CV. Pustaka Seti, 2007 ), Cet III, h. 88. 
- Yang kedua Far' u (cabang) adalah suatu peristiwa yang tidak terdapat di dalam Nash al - Qur' an dan al - Hadist. Peristiwa cabang yaitu mengenai Hukuman bagi Nabi Palsu.

- Yang ketiga Hukum Ashl (hukuman pokoknya) ialah hukum syara yang ditetapkan oleh Nash al - Qur' an dan al Hadist. Hukuman bagi seseorang melakukkan perbuatan Jarimah Riddah adalah hukuman mati.

- Dan yang keempat Tllat (sifat) yaitu suatu sifat yang terdapat pada $A$ shl. 'ilat yang terdapat dalam jarimah Riddah adalah seorang Muslim yang keluar dari Agama Islam baik dengan perkataan, perbuatan dan keyakinan. Sedangkan Nabi Palsu 'ilatnya yaitu seseorang yang sebelumnya iman kepada Allah SWT dan Nabi Muhammad SAW, setelah orang tersebut menemukan suatu hal yang menurut dia adalah benar. Kemudian dirinya meyakini hal tersebut. Dan mengaku sebagai Nabi setelah Nabi Muhammad SAW.

Selanjutnya Jarimah Riddah ( murtad) dapat terpenuhi apabila semua unsur - unsurnya sudah dilakukan oleh pelaku, Unsur Riddah antara lain :

- Kembali ( keluar) dari Agama Islam. Seseorang yang dapat dikatakan keluar dari Agama Islam dengan salah satu tiga cara yaitu, dengan perbuatan, perkataan dan keyakinan.
- Berniat untuk melawan hukum. ${ }^{30}$

Dalam buku Pidana Mati Dalam Hukum Pidana Islam bahwa Jarimah Riddah (murtad) terbagi menjadi tiga macam antara lain; sebab perkataan, perbuatan dan keyakinan. Apabila ditinjau dari segi kejahatan yang menggangu ketentraman umum yang ditimbulkan dari orang yang Murtad, dapat dibagi menjadi dua macam antara lain: Yang pertama, orang Murtad yang tidak mengadakan permusuhan dengan kaum Muslimin yaitu orang Murtad yang tidak melakukan perbuatan lebih jauh setelah dia keluar dari Agama Islam. Dan Yang kedua, orang Murtad yang mengadakan permusuhan dengan kaum Muslimin adalah melawan atau menentang kaum Muslimin baik dengan perbuatan maupun dengan perkataan, seperti mengangkat senjata, mencela dan menghasut. ${ }^{31}$

Kemudian menurut Aqidah Ahlus sunnah Wal Jama'ah bahwa Riddah ( murtad) terbagi menjadi tiga macam yaitu :

a. Riddah Qauliyyah ( perkataan ) ialah seseorang yang mengucapakan sesuatau sehingga dengan ucapanya dapat menyebabkan orang tersebut menjadi

30 Abdul Qadir Audah, Ensiklopedi Hukum Pidana Islam, Judul Asli at - Tasyri al - Jina'i al - Islamiy Muqaranah bil Qanunil Wad' ly, penerjemah, Alie Yafie dkk, ( Jakarta : PT. Karisma Ilmu, 2008 ), Cet I, h. 267.

31 Noer Wahidah, Pidana Mati Dalam Hukum Pidana Islam, ( Surabaya : al - Ikhlas, 1994), Cet I, h. 66 67. 
Murtad. Misalkan mencaci maki Allah SWT, Para Nabi dan Rasulnya. Sesuai dengan sabda Nabi Muhammad SAW :

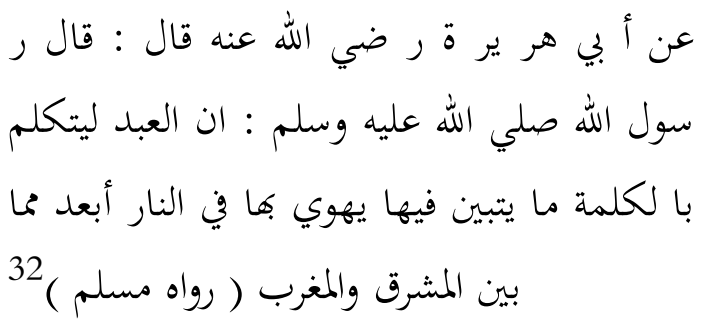

Artinya; Diriwayatkan dari Abi Hurairah r.a., bahwa Rasulullah SAW bersabda sesungguhnya seorang hamba yang mengucapkan perkataan ( yang melecehkan atau menghina Allah SWT atau syariatnya ) yang tidak dianggapnya bahaya, ( padahal perkataan tersebut ) dapat menjerumuskannya ke ( dasar ) Neraka ( yang kedalamanya) lebih jauh dari pada jarak antara timur dan barat. ( HR. Muslim )

b. Riddah Fi' liyah ( perbuatan ) adalah seseorang yang dengan perbuatannya dapat menyebabkan dia menjadi Murtad. Seperti melempar al - Qur' an dan al Hadits ketempat - tempat yang kotor, atau menginjak - nginjak al - Qur' an maupun al - Hadits, sujud kepada matahari dan rembulan. Firman Allah swt surat Fusilat ayat 37 yang berbunyi :

32 Imam Abi al- Husaini Muslim bin al - Hajaj, Shahih Muslim, 2003, Jus IV, h. 224.

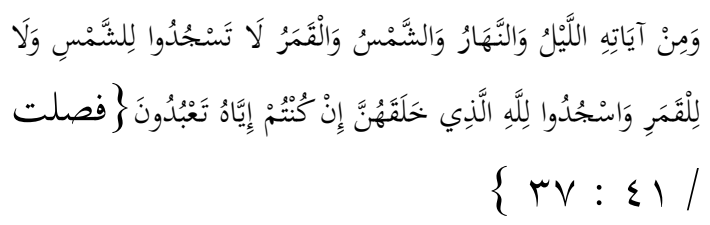

Artinya : "Dan di antara tanda-tanda kekuasaan-Nya ialah malam, siang, matahari dan bulan. janganlah sembah matahari maupun bulan, tapi sembahlah Allah yang menciptakannya, jika ialah yang kamu hendak sembah". ( QS. Fusilat $41: 37$ )

c. Riddah Qalbiyyah ( hati ) yaitu seseorang yang sebelumnya mengimani kepada Allah swt dan Rasulnya, setelah itu dia tidak mengimaninya karena disebabkan dari berbagai sebab. Antara lain bahwa Allah adalah benda atau roh, meyakini bahwa Allah swt berada di semua tempat atau dia meragukan adanya Allah swt. Firman Allah swt surat al - Hujarat ayat 15 yang berbunyi :

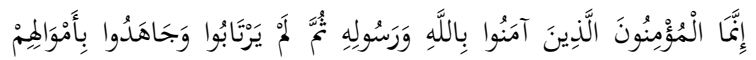

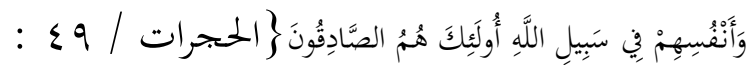
$\{10$

Artinya : "Sesungguhnya orang-orang yang beriman itu hanyalah orang-orang yang percaya (beriman) kepada Allah dan RasulNya, Kemudian mereka tidak ragu-ragu dan mereka berjuang (berjihad) dengan harta dan jiwa mereka pada jalan Allah. mereka Itulah orang-orang yang benar". ( QS. al - Hujarat $49: 15$ )

Dapat diambil kesimpulan bahwa bentuk - bentuk tindak pidana penodaan 
Agama yang diqiyaskan dengan Jarimah Riddah terbagi menjadi tiga macam yaitu Riddah Qauliyyah ( perkataan ), Riddah Fi' liyah perbuatan ) dan Riddah Qalbiyyah ( hati ). Riddah adalah suatu perbuatan seseorang muslim yang pada awalnya sudah menyatakan beriman kepada ajaran Allah SWT dan Rasul Nya, serta taat kepada perintah dan menjauhkan laranganNya, setelah itu dia keluar dari Agama Islam kepada kekafiran baik dengan niat, perbuatan dan ucapan yang menyebabkan kekafiran. Sedangkan hukuman bagi yang melakukannya yaitu darahnya halal untuk ditumpahkan.

\section{Penodaan Agama dalam Hukum Positif} Indonesia

Dalam hukum Indonesia KUHP (WVS) sebenarnya tidak ada bab khusus mengenai delik agama meski ada beberapa delik yang sebenarnya dapat dikategorikan sebagai delik agama. Istilah delik agama itu sendiri sebenarnya mengandung beberapa pengertian sebagai delik menurut agama, delik terhadap agama, delik yang berhubungan dengan agama. Oemar Seno Adji yang dikutip Barda Nawawi Arief menyebutkan bahwa delik agama hanya mencakup delik terhadap agama dan delik yang berhubungan dengan agama. Apabila diperhatikan sebenarnya delik menurut agama bukan tidak ada dalam KUHP meski hal itu tidak secara penuh dalam KUHP seperti delik pembunuhan, pencurian, penghinaan dan yang lainnya.

Pasal 156 a sering dijadikan rujukan hakim untuk memutuskan kasus penistaan / penodaan agama, bunyi selengkapanya adalah Dipidana dengan pidana penjara selama-lamanya 5 tahun, barang siapa dengan sengaja dimuka umum mengeluarkan perasaan atau melakukan perbuatan, yang pada pokoknya bersifat permusuhan, penyalahgunaan atau penodaan terhadap suatu agama yang dianut di Indonesia, dengan maksud agar orang tidak menganut agama apapun juga yang bersendikan ketuhanan yang maha esa.

Pasal tersebut dapat dikategorikan sebagai delik terhadap agama. Asumsinya, yang ingin dilindungi pasal ini, perlu dilindungi dari kemungkinan-kemungkinan perbuatan orang yang bisa merendahkan dan menistakan simbolsimbol agama seperti Tuhan, Nabi, Kitab suci dan sebagainya. Perlu difahami bahwa pasal 156 a tidak berasal dari wetbook van strafrecht (WVS) Belanda, melainkan dari UU No. I / PNPS / 1965 tentang pencegahan dan atau penodaan agama. Pasal 4 Undang-undang tersebut langsung memerintahkan agar ketentuan diatas dimasukkan kedalam KUHP. ${ }^{33}$

33 Rumadi, Delik Penodaan Agama dan Kehidupan Beragama Dalam RUU KUHP, (Jakarta: Yayasan Tifa), 2007, h. 10-12. 
Terdapat beberapa kasus di Indonesia yang telah diputus pengadilan negeri mengenai tindak pidana penodaan agama, diantaranya kasus penodaan agama yang dilakukan oleh lia Aminuddin dan Ahmad Musaddeq. Ahmad Musaddeq melakukan Tindak Pidana Penodaan Agama karena Ahmad Musaddeq berkeyakinan bahwa setiap yang dilakukan dalam mengajarkan al - Qiyadah al -Islamiyah merupakan jalan menuju kebenaran atau Shirathol Mustaqim, selain itu Ahmad Musaddeq berkeyakinan 100 \% bahwa Allah kembali akan membangkitkan Dien Nya diwaktu yang tidak terlalu lama lagi, dan sebagai putra bangsa Indonesia yang sangat merindukan bangsa ini menjadi pemimpin dunia Islam khususnya dan pemimpin dunia umumnya. ${ }^{34}$

Sedangkan Lia Aminuddin yang disebut Lia Eden dinyatakan melakukan Tindak Pidana Penodaan Agama karena menyatakan dirinya didatangi oleh makhluk gaib yang kemudian mendampinginya serta memberikan ajaran dan tuntunan Agama Islam. Menurut Lia Eden makhluk itu mengaku sebagai Malaikat bernama Habib al - Huda, selanjutnya dia menyatakan bahwa pendampingannya itu sebenarnya adalah Malikat Jibril. Kemudian Lia Eden juga menafsirkan al -Qur' an surah an - Najm ayat 6

34 Putusan Pengadilan Negeri (PN) Jakarta Selatan Tentang Penodaan Agama No. 277 / Pid. B / 2008 / PN. Jkt. Sel, h. 3. yang ditafsirkan sebagai berikut "Jibril menjadi berwajah perempuan tapi Lia menjadi sosok kelaki lakian yang tegar, aktif tapi sensitive. Dialah Jibril yang menjelma manusia dengan sempurna sebagai sosok. Lia Eden". ${ }^{35}$

Diantara faktor - faktor tersebut yang melatarbelakangi seseorang melakukan Tindak Pidana Penodaan Agama. Ada faktor yang dijadikan dasar seseorang untuk melakukan Tindak Pidana tersebut yaitu penafsiran kata ( yang artinya “ Penutup para Nabi dan Rasul “ sedangkan menurut Ahmad Musaddeq tidak mutlak berarti Nabi terakhir atau Nabi penutup dapat diartikan cincin atau kesempurnaan, jadi kata ( خا تم النبين ) yaitu “ Nabi yang sempurna “. Sehingga dihadapan 54 umatnya AM mengikarkan atau mengumumkan dirinya sebagai Rasul dengan gelar al- Masib alMaw' ud yang artinya " juru selamat yang dijanjikan". Pada saat itu Terdakwa berkata “ yang percaya kepada saya sebagai Rasul, silahkan maju kedepan untuk bersyahadat, kemudian mereka mendekat kepada Terdakwa dan Terdakwa mengajarkan kalimat syahadat dengan berbahasa Arab yang berbunyi :

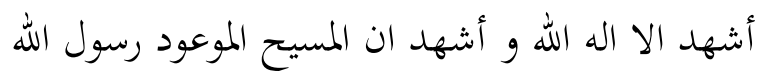

35 Putusan Pengadilan Negeri ( PN ) Jakarta Pusat Tentang Penodaan Agama No. 677 / Pid. B / 2006 / PN. Jkt. Pst, h. 6. 
Yang diterjemahkan kedalam bahasa Indonesia yang berbunyi "saya bersaksi tiada illah selain Allah dan saya bersaksi anda al Masih al-Maw' ud utusan Allah. Setelah mereka memahami, kemudian secara bergantian maju kedepan satu persatu sambil berjabat tangan dan menatap mata, mengucapkan kalimat syahadat tersebut.

Selain itu AM juga mengajarkan pelaksanaan shalat dalam sehari semalam hanya satu kali yakni shalat malam atau yang disebut qiyamullail sebanyak 11 rakaat dengan menghafal al- Qur'an dan belum mewajibkan shalat lima waktu, tidak mewajibkan melaksanakan ibadah puasa di bulan Ramadhan, serta belum melaksanakan zakat tapi hanya melaksanakan shadaqah dalam arti untuk membersihkan diri atau penebus dosa, AM belum mewajibkan bagi yang mampu untuk melaksanakan ibadah haji karena menurut AM ibadah haji hanya berkumpul.

AM selaku pemimpin komunitas al Qiyadah al - Islamiyah tidak memiliki rukun Islam sebagaimana rukun Islam yang dianut di Indonesia, akan tetapi memiliki program pengabdian antaralain; Menjalankan shalat qiyamullai, Tahfis Qur'an atau menghafal al Qur'an, Melakukan talwiyah atau da'wah, Melakukan 'Ta' lima tau peningkatan keilmuan tentang Islam, Penetapan atau penertiban shof dalam arti struktur kepemimpinan al- Qiyadah al- Islamiyah dan Melakukan shadaqah.

Berdasarkan perbuatan tersebut AM dianggap telah memenuhi konstruksi hukum seperti diatur dalam pasal 156 huruf a KUHP yaitu Unsur barang siapa, Dengan sengaja di muka umum. Serta Mengeluarkan perasaan atau melakukan perbuatan yang pada pokoknya bersifat permusuhan, penyalah gunaan atau penodaan Terhadap suatu Agama yang dianut di Indonesia dan dijatuhi Pidana yang setimpal dengan perbuatannya yaitu Pidana penjara selama 4 (empat) tahun dikurangi masa penahanan sementara.

\section{Penutup}

Menurut hukum pidana Islam bentuk tindak pidana penodaan Agama dapat diqiaskan dengan Jarimah Riddah dan dijatuhi hukuman sesuai dengan hukuman riddah sedangkan di Indonesia hukum positif juga mengatur mengenai tindak pidana penodaan agama yang terdapat di dalam KUHP pasal 156 dan 156 a seperti yang digunakan majlis hakim dalam memutus perkara No 227/Pid.B/2008/PN. Jkt.Sel

\section{Daftar Pustaka}

Alwi, Hasan dkk. Kamus Besar Bahasa Indonesia Edisi Ketiga, Jakarta : Balai Pustaka, 2005. 
Syariah: Jurnal Ilmu Hukum dan Pemikiran

Vol. 17. No. 1 Juni 2017
Tindak Pidana Penistaan Agama ...17-31

Rina Septiani
Audah, Abdul Qadir. al - Tasyri al - Jina'i al Islami. Maktabah : Dar- al - Urbah. 1963.

C. S. T. Kansil, Christine. S. T. Kansil. Kamus Istilah Aneka Hukum. Jakarta : PT. Surya Melti Grafika, 2001.

Daly, Penuh. Hukum Perkawinan Islam. Jakarta : PT. Bulan Bintang, 1988.

Haroen, Nasrun. Ushul Fiqih I. Jakarta : PT. Logos Wacana Ilmu, 1997.

Ibrahim Muhammad bin Abdullah al Buraikan, Pengantar Studi Aqidah Islam, Penerjemah Anis Matta. Jakarta : Robbani Perss.

Moeljatno. Kitab Undang-undang Hukum Pidana. Jakarta : PT. Bumi Aksara. 2001.

Munawwir, Ahmad Warso. al - Munawir Kamus Arab - Indonesia. Surabaya : Pustaka Progressif, 1997.

Muslich, Ahmad Wardi. Hukum Pidana Islam. Jakarta : Sinar Garfika. 2005

Muslim, Imam Abi al- Husaini bin al - Hajaj. Shabih Muslim. Libanon : Bairut, 2003.

Muhammad, Abi Hasan Nurudin bin Abdul Hadi'i Sannadi'i, Shabib Bukhari, Jus IV.

Nasution, Harun. Islam Ditinjau Dari Berbagai Aspek. Jakarta : Penerbit Universitas Indonesia, 2001
Putusan Pengadilan Negeri Jakarta Selatan No.227/Pid.B/2008/PN.Jkt.Sel

Rumadi. Delik Penodaan Agama dan Kebidupan Beragama Dalam RUU KUHP. Jakarta : Yayasan Tifa, 2007

Sulaiman, Abi Dawud bin Sajastani. Sunnab Abu Dawud. Lebanon : Darul Fiqri, 1994.

Suma, Muhammad Amin. Pidana Islam di Indonesia Peluang, Prospek, dan Tantangan. Jakarta : Pustaka Firdaus. 2001.

Syafe'I, Rachmat. Imu Ushul Fiqib Untuk UIN, STAIN, PTAIS. Bandung : CV. Pustaka Seti, 2007.

Usman, Superman. Yusuf Somawinata. Fiqih Mawaris. Jakarta : Gaya Media Pratama, 2002.

Wahidah, Noer. Pidana Mati Dalam Hukum Pidana Islam. Surabaya : al - Ikhlas, 1994.

Yusuf Ks. "Al-Qiyadah”. artikel ini diakses pada 28 November 2008 dari http://jowo.jw.lt. 